REVISTA CHILENA DE LITERATURA

Diciembre 2014, Número 88, 215-234

\title{
ELES ERAM MUITOS CAVALOS Y LAS BÚSQUEDAS DEL REALISMO ACTUAL
}

\author{
Matias Rebolledo Dujisin \\ Universidad de Chile \\ majorebo@gmail.com
}

RESUMEN / RESUMO / ABSTRACT

Existe una tendencia en la literatura latinoamericana de las últimas décadas de regreso a modos realistas de representación, intentando volver a vincular la literatura con la realidad concreta que se representa, con un compromiso social y político, pero a su vez cuestionando desde su misma enunciación los modos tradicionales de representación, que ya no se sostienen en un mundo donde las estructuras sociales, políticas y económicas se han transformado, cambiando la experiencia de lo real y cuestionando las posibilidades del lenguaje literario de comunicar dicha realidad material e histórica. Dentro de este panorama, Eles eram muitos cavalos (Luiz Ruffato 2001) aparece como uno de los ejemplos más radicales y complejos en esta tendencia literaria actual. En este artículo se estudiarán las características que permiten hablar de esta novela como una novela que propone un regreso crítico al realismo, con especial énfasis en algunos de los recursos y técnicas que utiliza, concentrados en tres dimensiones: el compromiso, la representación y el lenguaje, intentando comprender el sentido crítico que estos adquieren en la novela.

PALABRAS CLAVE: realismo, literatura brasileña, literatura contemporánea, nuevos realismos, literatura y sociedad.

Há uma tendência na literatura latino-americana das últimas décadas que pretende um retorno a modos realistas de representação que tentam vincular novamente a criação literária com a realidade fatual que é representada, com um engajamento social e político, mas pondo em tensão desde a sua enunciação os modos tradicionais de representação, que já não são válidos num mundo onde as estruturas sociais, políticas e econômicas têm sido transformadas, mudando a experiência do real e questionando as possibilidades da linguagem literária de comunicar essa realidade material e histórica. Dentro desse panorama, Eles eram muitos cavalos (Luiz Ruffato 2001) se apresenta como um dos exemplos mais radicais e complexos desta tendência literária atual. Neste artigo, estudaremos as características que 
possibilitam falar deste romance como um texto que propõe um retorno crítico ao realismo, destacando especialmente alguns dos seus recursos e técnicas, principalmente em três níveis: o engajamento, a representação e a linguagem, tentando compreender o sentido crítico que estes têm no romance.

PALAVRAS-CHAVE: realismo, literatura brasileira, literatura contemporânea, novos realismos, literatura e sociedade.

In the past few decades, Latin American literature has developed a trend towards a realist mode of representation, which is intended to re-establish the link between literature and factual reality, with an explicit political and social commitment. At the same time, it challenges traditional modes of representation, which are no longer sustainable in the context of the transformation of the social, political and economic structures of our time, which changes our perception of reality. It thus challenges the capacity of literary language to represent the concrete and historical reality. In this context, Eles eram muitos cavalos (Luiz Ruffato 2001) emerges as one of the most complex and extreme examples of this trend. This paper studies the elements that lead us to consider this novel as a case of this critical return to realism, with particular emphasis on some of the literary devices and techniques to which it recurs, belonging to three main dimensions: compromise, representation and language, analysing the critical sense in which they are used.

KEYWORDS: realism, Brazilian literature, contemporary literature, new realisms, literature and society.

La primera novela de Luiz Ruffato, Eles eram muitos $\operatorname{cavalos}^{1}$ (2001), ocupa un lugar fundamental no solo en la narrativa brasileña contemporánea, sino, particularmente, para la discusión crítica y teórica que ha problematizado el retorno a modos realistas de representación en la literatura brasileña de las últimas décadas. Esta vuelta al realismo parece ser un fenómeno común en los textos de avanzada que se producen actualmente en nuestro continente (algo similar ocurre en el cine y las artes plásticas), que ha ido ganando terreno en la discusión crítica latinoamericana. Una tendencia que supone una continuidad relativa con la tradición realista, pero que, a su vez, no propone una ruptura ni con la estética ni con el pensamiento postmoderno en general (el gran enemigo crítico de la estética realista), sino que lo incorpora en su reflexión, tal vez conciliando ambas perspectivas. El capitalismo neoliberal y la globalización, la virtualización de la realidad y claramente las nuevas tecnologías han creado nuevas percepciones de las estructuras y 
prácticas políticas y sociales, nuevas formas de sociedad, de marginalidad, y han visibilizado dimensiones de lo real antes olvidadas. Las posibilidades de comprender y comunicar lo real se transforman y se abren en múltiples dimensiones. De ahí que estos autores entiendan esta vuelta al realismo como una búsqueda, no como una propuesta unidireccional ${ }^{2}$. Aunque las propuestas tanto de autores como de críticos diverjan ${ }^{3}$, lo importante, a mi juicio, es la comprensión general de este fenómeno contemporáneo, que se puede caracterizar como una necesidad ética y estética de resignificar lo real en el arte, pero manifestando desde la misma textualidad sus propias limitaciones y contradicciones.

Situado en este panorama general de renovación de las formas literarias en Brasil, EEMC es fundamental como caso extremo de los nuevos realismos, en tanto condensa una parte representativa de las innovaciones y rupturas de estas propuestas, y que en este artículo se revisarán a través de los ejes del compromiso, de la representación de la experiencia y del uso del lenguaje. Es interesante, además, por lo explícito que ha hecho Ruffato su proyecto de retomar el compromiso del realismo unido a la clara necesidad de renovación de las formas ${ }^{4}$. Si la literatura es capaz de representar la realidad es también capaz,

\footnotetext{
"O escritor contemporâneo parece estar motivado por uma grande urgência em se relacionar com a realidade histórica, estando consciente, entretanto, da impossibilidade de captála na sua especificidade atual, em seu presente [...] passando a aceitar que sua 'realidade' mais real só poderá ser refletida na margem e nunca enxergada de frente ou capturada diretamente. Daí perceberam na literatura um caminho para se relacionar e interagir com o mundo nessa temporalidade de difícil captura. Uma das sugestões dessa exposição e a de que exista uma demanda de realismo na literatura brasileira hoje que deve ser entendida a partir de uma consciência dessa dificuldade" (Schøllhammer, Ficção 10-11).

Cfr. por ejemplo Salem Levy (174): “...em que sentido se pode falar hoje de um realismo literário? O primeiro passo a uma possível resposta é destacar, desde já, que não se trata de um realismo mimético, representativo. Ao contrário, a narrativa não funciona mais como instrumento de representação, como realidade segunda que remete sempre a uma natureza anterior, mas como uma realidade possível, ou seja, como uma realidade outra". También el concepto de 'rerealismo' y 'desrealismo' que propone Delgado (2005), o el 'realismo críptico' de Kohan (2005). Schøllhammer propone el concepto de "realismo afectivo" (2012). La diversidad de novedosos nombres para explicar un mismo fenómeno evidencia la multiplicidad de formas que adquiere este realismo, a la vez que lo poco concluyentes que son estas propuestas teóricas.

"A forma clássica do romance foi adequada para resolver problemas do início da Revolução Industrial. Depois, ela foi tendo que se adaptar aos novos tempos, até chegar a Joyce. O instrumento romance, com começo-meio-fim, não faz sentido diante da quantidade de informações de hoje, ficou obsoleto. Minha opção pelo fragmentário foi una provocação
} 
dentro de sus propios límites, de producir cambios en ella. La nueva novela debe responder a los nuevos desafíos de esta etapa de la (post)modernidad.

\section{COMPROMISO Y REALISMO}

La novela de Ruffato se incorpora, en términos generales, dentro de una larga tradición literaria, particularmente moderna, de la novela urbana ${ }^{5}$. Los procesos de modernización en Brasil, hacia los años 30, marcaron el comienzo de la literatura donde la ciudad se convierte en su eje temático e incluso estructural; en las últimas décadas, con la urbanización caótica, el crecimiento desmedido y sobre todo la visibilización de la marginalidad y violencias extremas de estas megaciudades, la urbe ha vuelto a ser un núcleo temático y reflexivo, que condensa una parte significativa de las grandes problemáticas actuales: la marginalidad, la violencia, la modernización, las nuevas identidades y ciudadanías. Son narrativas que interrogan el inescrutable e inexplicable paisaje urbano, intentando dar cuenta de una realidad altamente compleja, que sin duda escapa a cualquier explicación facilista. La ciudad contemporánea es una muestra tangible del fracaso del pensamiento ilustrado, y se ha convertido en un material dilecto de la literatura en la medida en que las respuestas parecen haberse agotado. Como señala Tonus, es la literatura que en su testimonio de la pobreza, la marginalidad y la ruina de la ciudad moderna entra en la discusión sobre la precariedad de la experiencia, donde "as ruínas urbanas, sob a forma de escombros, constituem tanto o elemento desencadeador do processo de criação artística como o do seu fracasso" (47).

Lo particular de EEMC es que dicha precariedad se instala formalmente desde su misma estructura, desde su enunciación. Aunque pareciera carecer de argumento, más bien lo que la novela elide es toda unidad narrativa; argumentos e historias tiene muchas, pero todas inconexas entre sí. La sola unidad que se puede encontrar en ella es precisamente la que desde el

mesmo. Quando eu publiquei o Eles eram muitos cavalos, muitos críticos torceram o nariz e disseram "mas isto não e um romance". Também acho que não é. Mas o que é? Não é um livro de contos. Quero colocar em xeque essas estruturas. Não quero fazer uma reflexão só sobre a realidade política, mas também questionar por meio do conteúdo a forma" (Ruffato "Entrevista").

Para una lectura de la representación de la ciudad en EEMC ver Rocha (en especial en su relación con la tradición precedente) y Barbosa da Silva. 
proyecto original del autor se puede dar: un día en la ciudad de São Paulo. Su narrativa fragmentaria, inconclusa, inconexa, se justifica y se fundamenta en la experiencia caótica de la misma ciudad, en la vivencia real de las millones de historias mínimas que pueblan ese vasto universo comprimido, y en la hipotética percepción de un flâneur postmoderno con cierta capacidad de oír y ver más allá de las fronteras de los sentidos.

La experiencia de la ciudad es una experiencia fragmentaria e inestable. Presenta siempre capas de realidad que nunca terminan por descubrirse, y todo proyecto de explicar o dar un sentido racional a la megalópolis parece haber fracasado. Y es que el pensamiento que dio alguna vez origen y sentido a la ciudad se ha perdido hace tiempo. De ahí se entiende que como proyecto estético y político, la representación de la ciudad (de los millones de individuos anónimos que la pueblan) exija buscar nuevas formas de representación ${ }^{6}$, cuyo primer gran intento es la novela que leemos. Entonces aparece otra forma de entender unitariamente esta novela, a partir del sentido crítico de lo que quiere representar: su título, tomado de unos versos de Cecília Meireles, que dicen "Ellos eran muchos caballos, / pero nadie sabe sus nombres, / su pelaje, su origen...", palabras que al terminar la lectura adquieren todo un nuevo sentido. Luego viene el epígrafe, del Salmo 82: “Hasta cuándo juzgaréis injustamente, defendiendo la causa de los impíos?", que establece una apelación directa al lector, lo que está en la base del efecto pragmático buscado por el texto.

De este modo, el autor expresa la necesidad de un compromiso real del escritor con su sociedad, la necesidad tanto ética como estética de dar cuenta de lo real, en su dimensión social y política, pero también haciendo expresa la imposibilidad de hacer esto a partir de los modos heredados de la literatura decimonónica o de las primeras décadas del siglo pasado. Una nueva estructura social y un nuevo individuo exigen nuevas formas de representación. Esto hace que su proyecto sea, a su vez, experiencial. No se trata de proponer un modelo, sino de dejar instalada la necesidad de

\footnotetext{
"Do meu ponto de vista, para levar à frente um projeto de aproximação da realidade do Brasil de hoje, torna-se necessária a invenção de novas formas de apreensão dessa realidade. Escrever romances baseando-se nas premissas do século XIX para descrever o caos do século XXI me parece um contrassenso. Por isso, acredito na busca de novas formas de expressão, em que a literatura dialoga com outras artes (música, artes plásticas, teatro, cinema, etc.) e tecnologias (internet, por exemplo) para a criação de uma linguagem que exprima esse novo indivíduo" (Ruffato, Segundo Caderno, O Globo, 1 de agosto de 2003; citado de Rocha 120-121).
} 
la búsqueda (como hará luego con la refundición de sus primeros libros de cuentos en el ciclo novelesco Inferno Provisório). La crítica postmoderna, particularmente desde Lyotard (2012), de que la literatura realista termina por 'normalizar' y por lo tanto consagrar el sistema del que surge, acusándola de un conservadurismo estético e ideológico, que aspira a un (re)conocimiento de mundo que supone certezas morales, totalidad, coherencia experiencial, encuentra un previsible eco en la propuesta tanto estética como conceptual de Ruffato. Es por eso que, en el pensamiento del autor, se hace necesaria la transformación del realismo en una estética de y para su tiempo, si quiere tener alguna validez estética y política.

El resultado de esta recuperación y ruptura de una tradición, en este caso, es un texto que se incorpora al eterno debate de si es realmente una novela. Como veremos, el solo hecho de que suscite esta discusión está también en el nivel de compromiso que propone el autor: estéticamente, en tanto la literatura debe ser una búsqueda de encontrar siempre nuevas vías de expresión, acorde a los tiempos y las necesidades expresivas del autor; éticamente, pues, como señala Ruffato, el regreso al realismo se da también por el replanteamiento de formas que fueron creadas para criticar o cuestionar otras formas económicas y sociales, y de ahí que, en su visión, la mera enunciación de la novela a la manera de la novela decimonónica se condice con la ideología conservadora y reaccionaria, que pretende presentar discursivamente una naturalización de las formas económicas del pasado, fundamentalmente burguesas; es decir, un discurso acomodaticio para el lector, que encontrando estructuras (literarias) familiares reconoce, y termina aceptando, el estado de cosas como lo 'normal' (en tanto familiar). El discurso literario crítico, rupturista y políticamente comprometido, argumenta implícitamente Ruffato, si quiere realmente captar y representar la experiencia del neoliberalismo y sus contradicciones internas, sus (nuevas) estructuras económicas, sociales y de clase, y de este modo ser realmente un elemento de reflexión y disrupción, debe desfamiliarizar las estructuras literarias heredadas del pasado ${ }^{7}$.

\footnotetext{
Esto se condice plenamente con los propósitos del realismo que, buscando un objetivo similar, pero en el contexto de la primera industria, creó y experimentó con formas, hoy ya canónicas, que en su tiempo crearon el mismo efecto de ruptura con la tradición precedente, la misma (o similar) búsqueda de representación de un modelo político y social sin precedentes a partir de nuevas formas literarias: el manejo del tiempo del relato, el perfeccionamiento del uso del indirecto libre, la individualización de personajes, historias, y sobre todo de la voz narrativa, la adaptación del lenguaje coloquial, la ampliación del repertorio de temas y clases
} 
En conclusión, el compromiso que se presenta en EEMC es un compromiso con el lenguaje y el medio artístico, y también social y político, como medio (posible) de transformación. Lo que está replanteándose en la forma de la novela, como veremos inmediatamente a continuación, es la posibilidad misma de la representación, una vez que ésta se ha (aparentemente) clausurado, tensionando al máximo los límites de la representabilidad a través del lenguaje, de los signos convencionales y abstractos y puramente conceptuales del lenguaje escrito. Ruffato se instala en un nuevo contexto, neoliberal y globalizado, rescatando la falta de cohesión y de macro-sentido de la experiencia cotidiana, revelando las estructuras sociales aparentes, que ya no encajan en los modelos tradicionales que explicaban dichas estructuras.

\section{FRAGMENTARIEDAD Y EXPERIENCIA}

La propuesta de EEMC hay que analizarla tanto por su estructura formal cuanto por su contenido. No hay manera alguna de separar ambas dimensiones, en lo que a este análisis respecta. Como no es posible sintetizar su argumento, es necesario antes que nada una descripción formal. EEMC presenta 70 fragmentos, sin ningún tipo de continuidad, que pueden leerse como cuentos (solo algunos de ellos, y en general de manera bastante inconclusa), como simples fragmentos poéticos, pastiches, pero nada parecido a una forma cercana a la novela tradicional. El número y el orden de estos fragmentos parecen ser irrelevantes ${ }^{8}$. Su única continuidad está dada por el espacio, la

sociales representables, la ambigüedad en la estructuración de la historia y sobre todo del juicio moral, etc. (cfr. Auerbach 2001; Lukács 1965, 1966; Villanueva 2004). El gran problema de Lukács como teórico fue precisamente el no reconocer que la estructura y estilo de los textos deben responder a la realidad (material e histórica, si se quiere) de su tiempo preciso; como señala Dentith (48-49), este gran teórico marxista fue 'ahistórico' al reconocer que el realismo solo fue posible por la etapa en el desarrollo de la sociedad burguesa del XIX, pero criticando las nuevas formas literarias que surgen de otro periodo económico y social, y fue no-dialéctico ("undialectical") en catalogar a las nuevas formas literarias (particularmente naturalismo y modernismo) como perversiones al realismo, y no como progresiones naturales del arte (acorde a su tiempo).

Al menos esa es la propuesta del autor, que en diversas oportunidades ha señalado que su intención original era presentar una especie de libro-objeto en que las 70 secuencias vinieran en hojas separadas dentro de un sobre y que el lector las leyera en el orden que quisiese; lo cual, claro, era editorialmente imposible, pero al menos revela la estructura deliberadamente 
ciudad de São Paulo, y el tiempo, el 9 de mayo de 2000. Pero temáticamente son absolutamente variados y discontinuos: unas ratas que entre la basura se comen un bebé abandonado; el padre sin dinero que quiere pero no puede robar unos pañales para su hijo recién nacido; el primer encuentro de un grupo de swingers; el taxista que cuenta amenamente su vida a un pasajero; la reunión anual de un grupo de amigos en sus cuarenta; o, simplemente, algunas secuencias que no son más que listados (los libros en una biblioteca, un menú, anuncios de periódico). Los temas y clases de personajes son tan variados como los estilos de cada secuencia. Es cierto que la marginalidad en diferentes facetas es lo más recurrente, así como la 'tragedia cotidiana' de estas múltiples subjetividades. Eso es esperable en un texto programáticamente crítico de la sociedad. Pero hay que reconocer que ni todas las historias son de personajes marginales (el empresario con su hijo, el profesor de filosofía), ni menos tampoco que todas ellas presenten una mirada pesimista sobre la realidad representada.

La conformación de este texto nos permite discutir un primer elemento propio de la novela, a mi juicio fundamental, para comprender su dimensión realista, y su posición dentro de lo que llamo aquí los nuevos modos del realismo, evidenciando formalmente la propuesta del autor de la necesidad de volver a modos 'representativos' (y comprometidos) de la literatura, pero a la vez adaptando su forma a su contemporaneidad, y yo diría reconociendo la visión crítica que instaló la generación precedente. Por una parte, recoge algo que ya se hacía manifiesto desde la primera literatura modernista: la evidente certeza de que es imposible comprender el mundo en su totalidad, que solo tenemos experiencias subjetivas de él, y que, desde este punto de vista, no hay nada más artificioso y falsamente 'ordenador de mundo' que un narrador omnisciente absoluto.

El hecho de que no tengamos grandes certezas, establecidas fundamentalmente desde una mirada única, uniformadora, compele al autor a crear textos en que lo único que poseemos son conciencias que perciben, que viven su propia historia, desde una subjetividad que parece ser la única posible certeza (" $¿$ san pablo es allá afuera? ¿es aquí dentro?”, p. 100), indiferentemente de la voz que efectivamente cuente la historia. Como cada secuencia es única temática

precaria de la novela. En la novela que leemos existe, eso sí, una cierta secuencialidad, con los fragmentos que la abren y la cierran y, sobre todo, porque se puede seguir una cierta sucesión temporal entre fragmento y fragmento, desde el amanecer hasta la noche. 
y estilísticamente, no queda más que seleccionar algunas para su análisis. Este ejemplo (secuencia 6: "madre", pp. 18-20) ilustra muy claramente la 'objetividad subjetiva' de la novela, así como la rica utilización de recursos grafemáticos que la caracteriza':

La vieja, ojos abiertos de par en par, tenazmente pegada a la butaca número 3 de la línea Garanhuns-San Pablo, no duerme, hace ya cuarenta y ocho horas, en vilo por la velocidad del ómnibus, Dios mío, ¿para qué tanto correr? [...] ¡Dios mío!, solo se alivia en las paradas, acabado el sacudimiento, ¿Y ahora?, ¿Tá cerca?, ¿Paciencia, abuelita!, Todavía falta un poquito [...] Y la gente todavía consigue dormir mi Dios, la bocona cocodrilo, la bocona cocodrilo, ;hasta ronca!, ¡hasta babea!, ¿qué come?, se mezclan los distintos paisajes, ciudades enoooormes, pueblito que, izum!, pasó,

$\underline{\mathbf{Y}}$

Las cercas de alambre púa, las hachas, el pasto, las termitas, carcasas de buey, urubúes, cielo azul, cobras, seriemas, gaviotas, caga-cebos, [...] bichos, bananos, bicicletas, arbolitos, árboles, árboles, árboles,

\section{el motor zumbándole dentro del oído (zuuuummmm)}

$\underline{\mathbf{Y}}$

la caatinga, los campos, la caña, la banquina, la cañada, el río [...]

\section{cuidado cuidado cuidado cuidado cuidado cuidado}

el dolor, los dolores, las dádivas, el dolor, los dolores, edificios, la chimenea, el humo [...] las ventanas, las ventanas, carteros, el miedo, el meo, los muertos, los montes, las montañas, los muertos, los montes, las montañas, los

\section{$\underline{\mathbf{Y}}$}

\section{el motor zumbándole dentro del oído (zuuuummmm)}

\footnotetext{
Es muy difícil reproducir los textos de esta novela, tanto por la grafía, como por los anacolutos o los espacios en blanco, que pueden confundir al lector de este artículo a pensar que son espacios dejados por mí, o bien, que los cortes que yo hago son cortes propios del texto. En general intento reproducir lo mejor posible los cambios de grafía, y ser lo más explícito posible en los cortes que son del texto y las supresiones mías, que siempre vienen marcadas por corchetes y puntos suspensivos. Uso, además, la traducción al español ya que el original dificultaría aún más la comprensión de estos fragmentos.
} 


\section{[...] la planicie, el verde, lo ceniciento, las cenizas y el olor a}

\section{cuidado cuidado cuidado cuidado cuidado cuidado}

[...] el día verdecaliente, la tarde azulfresca, la noche de estrellas empolvadas, el mundo, mundo grande, que no se acaba más nunca, y Oh, abuela, ya estamos casi la vejiga hinchada, duele la barriga, la espalda, ;Ay!, las escaleras, ; $U y$ !, las piernas, ; $A y$ ! $: U y$ !, sin posición, Allá, abuela, allá las luces de San el hijo esperando ¡Tantos años! Ganarse la vida en Sanpablo, en el BrejoVelho Solamente volvió dos veces, mi Dios [...] y vamos entonces a esperarla para pasar el Día de la Madre con nuestra familia y todos estaremos muy felices no se preocupe tanto que yo la voy a buscar a la terminal recuerdos para todos de la vejiga inflamada, los intestinos pegajosos, ¿cómo leer la mirada del hijo?, saber si es feliz en el trabajo, en el casamiento, pero, $A y$, la vejiga, la barriga, la espalda, $; A y$ !, las escaleras, $; U y$ ! las piernas, $; A y !, ; U y$ !, sin posición.

En la terminal, de pie, se refriega las manos.

La intensa carga subjetiva de este fragmento se convierte a momentos en un listado de elementos perceptuales sin un fin narrativo propiamente tal, mientras la experiencia gráfica de la lectura se intenta parangonar a la superposición sensible de estímulos en la madre; no podemos vivir su experiencia, pero podemos suponerla. Y en su devaneo se cristaliza la experiencia del migrante (tal vez la figura social más representativa del Nordeste), de la mayor parte de la clase obrera en estas grandes ciudades (como el mismo Ruffato, proveniente del pequeño pueblo de Cataguases y 'adoptado' por São Paulo), y sobre todo de la madre, que ya no sabe leer la mirada del hijo.

En esta extrema subjetivización de la representación y en su estructura formal se está, de paso, desacreditando nuevamente el discurso de los grandes relatos, como fuera propuesto por Jameson. Así, no tenemos más que los pequeños, ínfimos relatos del día a día, y todos los elementos que permiten comprender y armar una totalidad de cada fragmento se han elidido, puesto que la novela se vive en su estricto presente, mientras el pasado es solo una abstracción que podría (o no) explicar el día actual, pero es tan evanescente como el tiempo contemporáneo ${ }^{10}$. Cómo termina cada historia (aun suponiendo

10 Uno de los grandes logros de la novela realista es la creación de distintos dispositivos narrativos que le permitieron explotar al máximo la perspectiva y, algo menos estudiado, el manejo del tiempo narrativo, que manipularon para acercarse a la percepción sensible del 
que hay alguna historia que contar), evidentemente siquiera alcanza a ser una posibilidad. Se presentiza al máximo la experiencia, y no hay sino guiños al futuro ${ }^{11}$. La idea de 'historia mínima' se lleva a su máxima expresión, en cuanto son relatos sin principio ni fin (en el marco discursivo de la novela), que solo tienden evanescentes lazos con lo que está más allá. De allí que, a mi juicio, el 'efecto de lo real' o, más específicamente, siguiendo a Pam Morris, el 'efecto empírico'12 de esta novela no se da por la proliferación del detalle concreto 'inútil', que para Barthes pierde su significación como signo concreto denotativo pasando inmediatamente a su connotación: lo real; tampoco por la estructuración de las acciones o las referencias culturales compartidas, que permiten al lector participar de la historia como una experiencia vivencial, mientras que las referencias forman una red de citas implícitas que crean la sensación de un conocimiento compartido, permitiendo al texto aparentar la completitud semántica de nuestra realidad empírica (Morris 101-108). Esas formas tan efectivas del realismo tradicional son abolidas por esta novela.

tiempo, con recursos hoy ya triviales. De ahí que Faulkner o Proust, maestros del tiempo narrativo, se puedan considerar en gran parte deudores de la tradición realista. Lo mismo ocurre en esta novela, en que el tiempo vuelve a ser un foco sensible relevante, modificando los dispositivos temporales con el fin de presentar una temporalidad acorde a otro tipo de experiencia sensible, y con otros fines.

11 Por ejemplo, en una secuencia muy "Molly Bloom", la número 67. "Insomnio" (151-153), oímos la voz del personaje que no cesa, que comunica las experiencias de un pasado supuesto, en un presente inmediato, por medio de una secuencia que queda abierta, y que, como señalaba, presenta un proyecto de futuro inconcluso: "mierda, mañana compromisos, frenos del auto, aceite, do you wanna dance?, fiesta, maria aparecida albino, rubia, cara de sueño, sol caliente [...] te van a destruir, te van a joder, mi tío voy a acabar con el asma de ese chico me tiró en el agua fría del río pomba, salí rojo, temblando, yo te amo, parís, te están cagando, tecnopop, el pito del guardia de la noche, las". Este ejemplo es claro en sí mismo, aunque engañoso en la medida en que la interrupción puede entenderse como, por ejemplo, la caída abrupta en el sueño. Sin embargo, una buena cantidad de secuencias terminan así, en un quiebre o interrupción abrupta, silenciando el fin posible del microrrelato.

12 A partir del concepto de "efecto de lo real", Pam Morris, basándose en el mismo Barthes, pero el de $S / Z$, propone una más detallada concepción de esta idea, en lo que llama el "efecto empírico" ("all those techniques by which realist writing seems to convey the experiential actuality of existence in physical space and chronological time", p. 101), el "efecto de verdad" ("it functions ideologically to affirm the availability, ultimately, of at least a degree of knowledge and enlightenment within the order of human existence", p. 109) y el "efecto del personaje" (como individualización de caracteres), además de destacar el rol del lector en el texto realista, en lo que llama, consecuentemente, el "efecto del lector". Cfr. 101-130. 
Entre otras cosas, según lo entiendo, porque esa estructura se convirtió de una manera de generar la sensación de estar 'viendo' una historia (semejante a una) real, a una manera de que el lector se sienta familiarmente 'leyendo una historia', en la medida en que dichas técnicas (relativamente novedosas en su tiempo) reproducen una estructura aprendida desde la acumulación de lecturas literarias y no desde la experiencia, que ya no se esfuerzan siquiera en asimilar o al menos simular verbalmente. Esa acumulación y esa estructuración tradicional desaparecen, y el efecto pretendido (real o empírico) se produce precisamente por esta ausencia. Me explico: tal cual las historias del presente vivido, el pasado relativo es solo un signo que permite comprender el presente. La historia que continúa es nada más que un signo ausente, una verdad por construir. Ninguna de las historias de esta novela acaba ${ }^{13}$; es el lector, en un rol activo, el que debe suponer un final para cada una de ellas, pero que en su precariedad, fragmentariedad y variedad no alcanzan a ser más que bosquejos, que tienen que ver más con el lector que con el texto, trasmitiendo hasta cierto punto la experiencia sensible del personaje. La ausencia de concreción en las historias, de un pasado que las explique, y de continuidad entre relatos, defamiliariza al lector con el molde clásico de la novela, y lo obliga a crear su propia representación, e incluso a representarse a sí mismo, desde su experiencia ${ }^{14}$.

La secuencia 17: "la espera" (41-44), por ejemplo, se arma casi como un cuento cerrado en el que el hijo de la casa parte a su enésima entrevista de trabajo fracasada, de lo que se deduce el sentido del título de la secuencia; sin embargo, abruptamente termina con un paréntesis (con cambio de grafía): "(Por la noche, recostada en el portal, olla a presión curvando la mano derecha, la madre ve el noticiero en la televisión, los colores escapan, manchan las paredes del comedor, el hijo salió a buscar trabajo, no volvió todavía, ni llamó por teléfono, ¿Habrá pasado algo, Dios mío?, en la pausa atraviesa el pasillo, pone la sopa knorr gallina criolla a recalentar)”. Ese quiebre produce

13 Hay, eso sí, algunas pocas secuencias que tienen unidad propia. Unas son las que no presentan ningún 'relato' propiamente tal. Pero también hay algunas, como la 20: "podríamos haber sido grandes amigos" (47-50), que perfectamente se pueden extrapolar y leer como un cuento cerrado. Pero es una de las pocas excepciones.

14 Son más que los vacíos del texto que todo lector debe completar, según Iser. O es un caso extremo de lector implícito, pero no con la mera intención de confundir al lector, sino creando la autoconsciente identificación entre éste y el lector real, al que EEMC apela directamente, constantemente. 
un cambio abrupto en el sentido que tenía tanto el título como la secuencia; pero no es más que un paréntesis, y un implícito punto suspensivo (mientras se vuelve a calentar la sopa).

Este presente casi absoluto y la necesaria inconclusión de los textos comienzan a tensionar los niveles en que actúa la mimesis; el silencio, el silencio abrupto, la interrupción, son formas de manifestar la irrepresentabilidad de lo que se presenta. Ejemplos vimos en la larga cita de "Madre", en "Insomnio" y en el paréntesis de "La espera". Pero en la macro estructura de la novela también hay una gran interrupción y un paréntesis. Las dos últimas secuencias no tienen número ni título; la penúltima es solo dos páginas consecutivas completamente negras (la interrupción), mientras que el final de la novela es un diálogo completamente entre paréntesis; de ese final me ocuparé más adelante.

Es en este silencio abrupto entre las sucesivas secuencias donde también se manifiesta el compromiso político y social, como efecto pragmático pretendido, que actúa tanto en la exigencia del lector para completar estas historias (si el lector 'sabe', también es que puede 'hacer' algo), es decir, tanto por la incompletitud, el vacío, como por la acumulación: es tal la diversidad de historias, personajes, situaciones, que pese a su brevedad la novela presenta uno de los panoramas más completos de la megalópolis de São Paulo, que en su estructura misma revela su precariedad, su inconsistencia, su falta de continuidad y soluciones. La suma de estas historias es una bofetada al lector que opera no por su individualidad (por separado, son historias tantas veces vistas o leídas), sino por el peso acumulado. Cada fragmento es una interrogación directa al lector, y la novela una crítica social total que exige una postura ética sobre ella ${ }^{15}$.

15 De manera similar, Salem Levy (178) propone que "[o romance] coloca o leitor de cara com o real, exigindo dele uma postura ética que se resume na pergunta: o que fazer quando se está diante de uma realidade inevitavelmente cruel? É do corte entre uma imagem e outra, do intervalo não-representado, não-dito, não-visto, que emana a presença do que estou chamando aqui de real. O real que não é a realidade, mas o impensável do pensamento, o irrepresentável da representação, o invisível do visível, ou seja, o que se expressa no vazio, no intervalo, no corte". 


\section{REALISMO DEL LENGUAJE}

Como era de esperar, la crítica ha fijado más la atención sobre esta novela en relación con su estructura, y la dimensión política o social ha quedado en un segundo plano, o solo en su nivel más explícito (los temas de algunas de las secuencias). Pero lo que se ha dicho en relación con esa estructura es, a su vez, de lo más diverso. Analizando las palabras de Ruffato, pareciera que intentara rehuir de la naturaleza misma de la novela y sus antecedentes históricos. Solo por dar un ejemplo, se ha propuesto que las setenta secuencias que la conforman son como flashes cinematográficos inconclusos, que presentan solo lo que la cámara podría mostrar, sin solución de continuidad, o bien una suma de cuentos unidos por un día y una ciudad, o que tiene una estructura dramática ${ }^{16}$. De este modo la novela, a juicio de algunos críticos, privilegiaría la imagen por sobre el lenguaje. Sin embargo, pienso, si bien en ciertos sentidos la novela es bastante 'visual', su realismo de hecho no pasa por la creación de un imaginario icónico fuerte que trascienda el lenguaje, sino todo lo contrario. Como texto absolutamente consciente de su contemporaneidad, la novela lleva al primer plano la dimensión material del lenguaje. Vale decir, en otro plano, su realismo es una puesta de manifiesto de su literalidad, de su ser antes que nada un constructo de lenguaje ${ }^{17}$. Las palabras no son el sustituto de ningún imaginario visual que quiere transparentarse detrás de la lectura (la más simplista de las visiones sobre el realismo, con una raigambre platónica). Es lenguaje, antes que nada, y el texto lo deja de manifiesto, hace de la palabra un medio expresivo y un medio material, manifestando en su enunciación la composición verbal como recurso estilístico, estético, material y significante.

$16 \quad$ Cfr. Salem Levy (173): "São como diferentes takes, ora mais nítidos, ora mais borrados, mas sempre uma imagem. As narrativas transmitem flashes da realidade, como se apanhados por uma câmera". También Barbosa da Silva (94): "No formato do texto, há uma conformação teatral. No coração da urbe, um drama que funde realidade e ficção, catarse e desafogo de sujeitos". Texto ora cinematográfico, ora dramático, ora poético, esta disparidad en las opiniones manifiesta la riqueza a la vez que complejidad de la novela; parece que es necesario recurrir siempre a otro género (u otro medio discursivo: las imágenes, el teatro) para explicar lo que de novela tiene este texto.

17 Creo que el ejemplo de "Madre" es suficiente para presentar la riqueza lingüística de la novela, que pasa por un excesivo uso de grafías diferentes, de signos verbales y paraverbales (como las dos páginas en negro), por la asociación fónica de palabras, por la organización de las líneas y la página, y, en fin, por un constante uso poético de la lengua. 
Personalmente pienso que uno de los aportes fundamentales de estos nuevos modos del realismo es que ha quedado como definitivamente anacrónica la radical separación entre compromiso, como un rasgo fundamentalmente de contenido, generalmente asociado a una transparencia formal y, por otro, los textos vanguardistas o rupturistas, cuyo compromiso parecía estar más con la forma. La discontinuidad y eterna derivación entre significantes y significados, y la ruptura radical con toda referencialidad a las que nos llevó la deconstrucción, habían transformado al lenguaje en un terreno de juego, o en juego, cuyo valor era radicalmente autotélico. La fe en que el lenguaje puede trascenderse a sí mismo, convirtiéndose en simple vehículo de imágenes e ideas, comenzó a desdibujarse dramáticamente ya desde Saussure, y la deconstrucción, aunque no solamente ella, nos mostró por qué. Creo, y así lo veo en un autor como Ruffato, que una vuelta atrás en esto sería caer en una ingenuidad representativa y en cierta medida poco comprometida. Sin embargo, estas aparentes limitaciones son utilizadas de manera positiva: el discurso se vuelve sobre el mismo lenguaje, develando su artificio, su materialidad, incluso su convencionalidad, solo que esto acontece al mismo tiempo en que es utilizado como un medio de comunicación efectivo. De paso, y por lo mismo, es posible un grado de compromiso (ético, estético, social y político) en el más tradicional de los sentidos. El lenguaje es también un contenido comunicado, a la vez que un significante expresado.

Me quiero detener en dos elementos no tan evidentes en este sentido (como la grafía o la poeticidad) que, pienso, ilustran el efecto de esta dimensión estética del lenguaje, su estructura y estilo, que también conforman algunos de los niveles de sentido del texto. Uno de ellos es el punto de hablada, pues, a fin de cuentas, ¿quién ve, quién habla en esta novela? El autor utiliza una variedad tan amplia de posibilidades narrativas: narrador omnisciente, en primera persona, heterodiegética de focalización interna, en indirecto libre o simplemente indirecto, la acotación dramática, la enumeración caótica, el verso. Todo esto aun dentro de un mismo fragmento. Incluso la ausencia de un narrador propiamente tal, puesto que nada efectivamente se cuenta en algunas secuencias ${ }^{18}$. Evidentemente, detrás de todo esto hay un claro autor implícito,

18 Convencionalmente podríamos decir que siempre hay un narrador. Pero en las secuencias 1: "Titular", donde solo se nos menciona la ciudad y el día; en la 18: "En la punta del dedo (1)", donde hay un listado de ofertas de trabajo del diario; y en la 68: "Menú", que es literalmente lo que el título dice, y otras secuencias, no hay más que enunciados que reproducen tipos específicos de discursos, sin un contenido narrativo propiamente tal. 
o una conciencia estructurante. Pero esta variedad casi aleatoria demuestra también una cierta indecisión, un cuestionamiento a las posibilidades de narrar, de decir lo que se quiere decir, de representarlo; es, por sobre todo, un juego, un artificio literario que, pienso, el autor no quiere esconder. Así, el narrador, incluso el más impersonal, en esta acumulación termina por develar que es un narrador, así como el autor implícito aparece en todo momento tirando los hilos de estos narradores inconsistentes e inconclusos. La novela se nos muestra así como acto narrativo en proceso, como construcción literaria, que tal vez quiere decir lo real, pero en su ser literatura.

El otro elemento que me parece interesante de esta imbricación entre la materialidad sígnica y su propuesta realista es la configuración o descripción que se da, en algunas secuencias, de los personajes. Nuevamente, escojo un fragmento de una secuencia que muestra con claridad mi punto, la 26: "pañales" (58-61):

El de seguridad, negro gigante, corpulento, impecable dentro del traje negro, abordó discretamente al negro flaquito, huesudo, camisa de jersey blanca vieja jeans inmundos zapatillas de suela gastada que empujaba un carro de supermercado hacía cerca de media hora-cinco paquetes de pañales descartables, una lata de leche nido.

El de seguridad, negro gigante, corpulento, impecable dentro del traje negro fue advertido por el jefe, que, vigilando las cámaras distribuidas por el hipermercado, notó que el negro flaquito, huesudo, camisa de jersey blanca vieja jeans inmundos zapatillas de suela gastada sin los dientes delanteros, después de circular por las góndolas, en el carro de supermercado diez paquetes de pañales descartables, se colocó en la fila de la caja, como eligiendo entre alguno de los clientes.

El de seguridad, negro gigante, corpulento...

Presentado de esta manera, el personaje se representa de manera profundamente visual, convirtiéndose, además, en un tipo, en un sentido lukacsiano ${ }^{19}$; es posible ver al personaje y sentirlo como parte de un todo social. Pero en su composición verbal, al constituirse de puros elementos externos, repetitivos,

19 Para Lukacs, "la categoría central, el criterio fundamental de la concepción literaria realista es el tipo, o sea, la particular síntesis que, tanto en el campo de los caracteres como en el de las situaciones, une orgánicamente lo genérico y lo individual [donde] confluyen y se funden todos los momentos determinantes, humana y socialmente esenciales, de un periodo histórico" (Ensayos 13). 
que reemplazan el nombre propio $^{20}$, y se reiteran una y otra vez, terminan por cosificar al personaje, transformándolo en esos objetos que se superponen a su 'humanidad'. Esto, nuevamente, trae una doble consecuencia: por un lado, se explicita el tipo en tanto construcción literaria, como acumulación verbal, como efecto del texto; por otra, se evidencia un discurso crítico subyacente que denuncia esta construcción social que caracteriza a los ciudadanos según categorías nominales, generalmente estereotipadas y vacías de todo contenido humano. Al cosificar verbalmente al personaje se tensiona precisamente esa cosificación discursiva que opera en la representación social.

Con estos últimos elementos quiero intentar mostrar cómo en su misma enunciación esta novela está por un lado recuperando la tradición realista fundamental, y a partir de ésta la más antigua visión de la literatura como mimesis y representación ${ }^{21}$; pero, por otro lado, como señalo, a partir de su propia enunciación, poniendo en tensión, cuestionando e incluso desmantelando la comprensión de lo que es la representación, sus posibilidades y sobre todo sus límites. Para Salem Levy, EEMC es realista en la medida en que comunica la experiencia, pero apartándose de la realidad concreta: "A transmissão da experiência é o que caracteriza o realismo de Eles eram muitos cavalos. A partir de sua ousadia com a linguagem, Ruffato promove um deslocamento da narrativa em relação à realidade concreta. Sua prosa é realista não porque tenta se colar ao mundo exterior, mas, ao contrário, porque se distancia dele, desloca-se, afirma-se enquanto ficção" (181). En estas últimas palabras se afirma lo que vengo sosteniendo. Pero, tal como lo plantea Costa Lima (especialmente en 313-328), para replantearse la mimesis hoy, es necesario tal vez entenderla como una serie de diferencias y no como un homólogo, en tanto es a partir de ese distanciamiento con lo que yo reconozco como real que puedo volverme hacia éste y re-conocerlo, mirarlo desde la mirada que el texto nos invita; desde este punto de vista, no creo que Ruffato simplemente se distancie del mundo exterior, sino que en un ejercicio representacional extremo deja los espacios lindantes entre lo representado y lo representable, decimonónico, y en este sentido juega un papel fundamental el nombre propio. Confróntese en este sentido Ian Watt (1957), para quien este movimiento hacia lo particular es una consecuencia del individualismo moderno (y, por lo tanto, producto del pensamiento, visión de mundo y sistema económico de la época), y es característico de la novela moderna.

$21 \quad \mathrm{Al}$ menos en un sentido aristotélico, como construcción convencional, y no como réplica de la realidad observable. 
llegando a representarse incluso a sí mismo como 'sujeto representador' y al texto como objeto y como ficción, y por medio de los silencios que el texto utiliza como marca estructural, y en este juego de diferencias, obliga al lector a autorrepresentarse como receptor literario y, sobre todo, como sujeto social.

Entonces es que el final de la novela se vuelve más significativo aún: luego de una interrupción de dos páginas en negro (el silencio absoluto de la representación) viene un diálogo dramático entre paréntesis, de una pareja que despierta en medio de la noche oyendo unos gemidos:

([...] -Debe haber sido un cuchillazo... por el modo...

- ¿Y no vamos a hacer nada?

-¿Hacer? ¿Hacer qué, mujer? Quédate quieta... ¿Y si hay alguien afuera? ¿Y si es una trampa?

[...]-Parece que pararon.

-¿Qué?

-Los gemidos. (Pausa) Sí... paró de verdad... ¿Vamos a ver ahora? $-¡$ ¡No!

-¿Por qué?

-Porque... porque todavía puede haber alguien allá... ¿Y entonces? Mejor dormir... Dale... date vuelta... date vuelta y duerme... Mañana... mañana vemos... Mañana vamos a saber... Duerme... Dale). (157-158)

Con este final, la novela deja instalada una pregunta en el lector: si éste, en su mundo real y concreto, no en su experiencia de lectura, también se dará la vuelta y dormirá; si esperará a mañana (total, mañana es otro día...), para 'saber' (y no para 'hacer'). Por eso planteo que la novela apela a lo real (lector incluido) desde la ausencia: el lector está en cada uno de los puntos suspensivos del fragmento anterior, mientras le susurran al oído, entre paréntesis, que él también está en el texto, que él también es uno de los muchos caballos sin nombre ni origen.

Esa es la apuesta de EEMC con lo real. El lenguaje logra trascender hacia la realidad que representa, comprometiéndose con ella, políticamente, pero sin pretender la transparencia del lenguaje (el ideal del showing de James), sino acosando al receptor desde su misma textualidad. De ahí que incluso la pregunta de si es o no es una novela (¿lo es?) forma parte indiscutible de su propuesta política y literaria. Son líneas que se cruzan. La textualidad es política. 
Quiero terminar con una reflexión algo anómala, en relación con el diseño de portada de la edición brasileña y el de la traducción. La edición brasileña (ver imagen 1) pone sobre un fondo granate "Eles eram muitos cavalos" repetido varias veces, en distintos tonos, con un estilo máquina de escribir, que deja huellas de impresión, superponiéndose. Textualidad sobre textualidad, este diseño enfatiza la dimensión discursiva y formal de la novela, invitando, tal vez, a leer políticamente la novela desde allí. La versión en español (ver imagen 2), en cambio, presenta varias figuras humanas pequeñas, solo sombras, borrosas y multiplicadas en toda la portada, excepto una, que es roja en vez de negra. La figura roja (que es la misma figura repetida, solo que en distinto color) destaca sobre las otras, pero sigue siendo tan anónima como las demás. Así, esta portada pone el énfasis en los "muchos caballos", en los seres anónimos de la vida contemporánea, que son brevemente convocados por el relato (como la figura roja), para seguir siendo tan anónimos como antes pero, tal vez (así lo quiere el texto), iluminados desde otra perspectiva, trayéndolos brevemente a presencia. Así, esta portada invita a leerla políticamente desde su dimensión social, dos caminos alternativos pero casi idénticos para leer esta novela que tensiona su mismo género desde dentro para volver a sentir el realismo como una propuesta literaria y social vigente.

Imagen 1

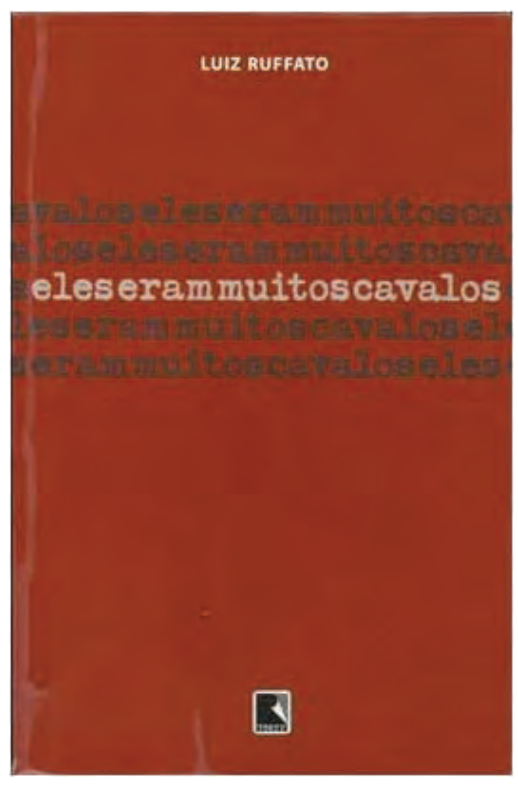

Imagen 2

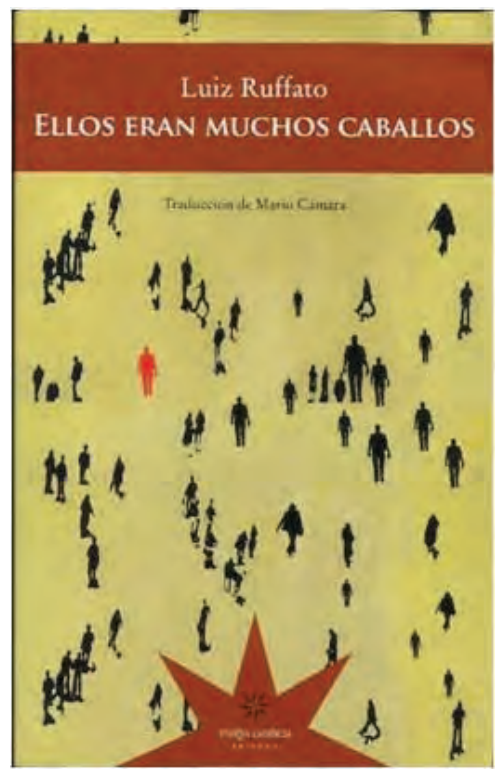




\section{BIBLIOGRAFÍA}

Auerbach, Erich. Mimesis. La representación de la realidad en la literatura occidental. México: Fondo de Cultura Económica, 2001.

Barbosa da Silva, Nádia Regina. "Urbe contemporânea: motivo e linguagem: Eles eram muitos cavalos, de Luiz Ruffato". Letras 34. Universidade Federal de Santa Maria (jun. 2007): 87-104.

Barthes, Roland. "El efecto de realidad". Barthes (et al.). Lo verosímil. Buenos Aires: Tiempo Contemporáneo, 1970. 95-102.

Bowlby, Rachel. "Foreward". Ed. Matthew Beaumont. Adventures in Realism. Oxford: Blackwell Publishing, 2007. xi-xviii.

Costa Lima, Luiz. Mímesis: Desafio ao pensamento. Rio de Janeiro: Civilização Brasileira, 2000.

Delgado, Sergio. "El personaje y su sombra. Rerealismos y desrealismos en el escritor argentino actual". BOLETIN del Centro de Estudios de Teoría y Crítica Literaria 12 (diciembre 2005).

Dentith, Simon. Realist Synthesis in the Nineteenth-Century Novel: 'That unity which lies in the selection of our keenest consciousness"". Ed. Matthew Beaumont. Adventures in Realism. Oxford: Blackwell Publishing, 2007. 33-49.

Kohan, Martín. "Significado actual del realismo críptico". BOLETIN del Centro de Estudios de Teoría y Crítica Literaria 12 (diciembre 2005).

Levine, George. "Literary Realism Reconsidered: 'The world in its length and breadth"'. Ed. Matthew Beaumont. Adventures in Realism. Oxford: Blackwell Publishing, 2007. 13-32.

Lukács, Georg. Ensayos sobre el Realismo. Buenos Aires: Siglo XX, 1965.

Problemas del Realismo. México: Fondo de Cultura Económica, 1966.

Lyotard, Jean-François. La condición postmoderna: informe sobre el saber. Madrid: Cátedra, 2012.

Morris, Pam. Realism. London and New York: Routledge, 2003.

Rocha, Rejane Cristina. "As formas do real: a representação da cidade em Eles eram muitos cavalos". "Estudos de Literatura Brasileira Contemporânea 39 (jan./jun. 2012): 107-127.

Ruffato, Luiz. Eles eram muitos cavalos. Rio de Janeiro: Record, 2012 (2001).

Ellos eran muchos caballos. Buenos Aires: Eterna Cadencia, 2010.

"Entrevista”. Folha de São Paulo. 19 de marzo de 2005. www1.folha.uol.com.br/ fsp/ilustrad/fq1903200507.htm

Salem Levy, Tatiana. "O silêncio da representação: uma leitura de Eles eram muitos cavalos". Estudos de Literatura Brasileira Contemporânea 22 (janeiro/junho de 2003): 173-184.

Schøllhammer, Karl Erik. "Realismo afetivo: evocar realismo além da representação". Estudos de literatura brasileira contemporânea 39 (2012): 129-148.

Ficção brasileira contemporânea. Rio de Janeiro: Civilização Brasileira, 2009.

Tonus, José Leonardo. "O discurso sobre a precariedade em Luiz Ruffato e Arlindo Gonçalves". Estudos de Literatura Brasileira Contemporânea 41 (jan./jun. 2013): 47-59.

Villanueva, Darío. Teorías del realismo literario. Madrid: Biblioteca Nueva, 2004.

Watt, Ian. The Rise of the Novel: Studies in Defoe, Richardson and Fielding. Berkeley: University of California Press, 1957. 